\title{
Biodynamics of Hepatitis C Virus in Haemodialysis Patients in Pahang
}

Mohammed Saad AM, Mohammed Imad AM, Aini HH, Seman MR

Department of Basic Medical Sciences, Kulliyyah of Medicine, International Islamic University Malaysia

\begin{abstract}
Introduction: HCV infection is frequent in patients undergoing maintenance haemodialysis, with prevalence between 8 and 10\%. Hepatitis $C$ has an adverse effect on both patient and graft survival in those who get renal transplants. There are relatively scarce reports on the natural fluctuation in viral load level in patients on chronic haemodialysis. Materials and Methods: This is a longitudinal short-term three months study, where 27 chronic haemodialysis patients infected with known HCV genotypes were recruited from seven haemodialysis centres in Pahang. Serum samples were collected monthly, both pre- and post-haemodialysis sessions, over a period of three months. Viral RNA was extracted from serum using QIAamp Viral RNA Extraction kit (Qiagen). The HCV viral load was measured using one-step reverse transcriptase qPCR (Applied Biosystems) targeting the $5{ }^{`} \mathrm{HCV}$ non-coding region (5’UTR). The serum a-IFN level was measured using commercial ELISA kit (Amersham, UK). Six biochemical liver function tests (AST, ALP, TP, albumin, ALT and TB) were also done for all pre-haemodialysis samples. Results: All patients showed persistent low level viral load that varied significantly over the study period $(p=0.001)$. HCV genotype 1 viral load was significantly higher than that of genotype 3. Conclusion: No apparent correlation could be recognized between the viral loads and the corresponding interferon-alpha levels which were detectable in only a few patients during the period of study.
\end{abstract}

KEYWORDS: HCV Genotypes, Haemodialysis, Biodynamics INTRODUCTION

This study is aimed at elucidating the biodynamics of $\mathrm{HCV}$ infection in haemodialysis (HD) patients as they are both more prone to HCV infection and also because they are considered as immunologically compromised. A limited number of articles were found in the surveyed scientific literature that looked into the biodynamics of HCV infection in general and in HD patients in particular. ${ }^{1-8}$ Fabrizi et al. ${ }^{7}$ studied the biological dynamics of viral load in patients infected with hepatitis $C$ virus associated with end-stage renal diseases who were undergoing maintenance haemodialysis, where the serum HCV RNA was measured monthly for 13 months using branched DNA signal amplification assay. He found that larger fluctuations in HCV RNA levels occurred in patients with persistent than in those with intermittent HCV viraemia. Moreover, in haemodialysis patients, the viral load was found by some researchers to be reduced immediately after dialysis sessions, but then gradually recovered to its basal levels after 48 hours, attributable to a dialysis-induced increase in plasma interferon-a level

Corresponding author:

Mohammed Imad Al-Deen Mustafa

Department of Basic Medical Science, Kulliyyah of Medicine, International Islamic University Malaysia P. O. Box 141, 25710, Kuantan, Pahang, Malaysia phone (office): +609-5716606

E-mail: imad@iium.edu.my that they were able to detect immediately after these sessions. ${ }^{2,3}$

Altiparmak et al. ${ }^{2}$ had studied the relationship between histological damage, viral load and serum transaminase levels in patients with chronic hepatitis $C$ but found no relationship between these parameters, suggesting that the histological damage to liver cells in these patients is probably not directly mediated by the virus infection. In addition, Berger et al. studied the relationship between different genotypes and viral load, and conclude that statistically significant higher HCV RNA titres were observed in haemophiliacs infected with HCV genotype 1 in comparison to those infected with other genotypes. ${ }^{6}$

\section{MATERIALS AND METHODS}

The study design used was longitudinal with three months data collection duration. The study aimed at elucidating: 1) the dynamic changes of viral load with time, 2) the relationship between the functional status of the liver and viral load, and 3) the relationship between $\mathrm{HCV}$ genotypes and viral load.

\section{Patients}

Twenty-eight patients from seven participating HD centres in Pahang were targeted in this study but one patient withdrew during the study. Inclusion criteria were age $\geq 18$ years, positive ELISA for anti-HCV, positive RIBA tests and/or rt-PCR and genotyped HCV. Patients co-infected with HBV/ HIV and those who refused to sign the informed 
consent form were excluded. The institutional (Faculty of Medicine, International Islamic University Malaysia) ethical committee approval was obtained. Laboratory Diagnosis of HCV All serum samples used in this study were collected from patients who already have been tested positive for anti-HCV antibodies in ELISA screening test and confirmed by RIBA and/or RT-PCR targeting a 212 bp stretch of the 5 'UTR region. The Malaysian Ministry of Health requires all patients undergoing $H D$ treatment to be screened for anti-HCV antibodies every three months.

\section{Blood Samples}

Two blood samples were collected, one each before and after the haemodialysis sessions. The samples were obtained before the patients were infused with heparin in order to avoid its PCR-inhibiting activity. Each sample is divided into two tubes; one for the molecular and the other for the liver biochemical profile. Blood samples were collected at 3 points in time one month apart. Within 1 hour after venopuncture, sera from all samples were aliquoted and stored immediately at $-70^{\circ} \mathrm{C}$ until used.

\section{Extraction of Viral RNA}

HCV RNA was extracted from $200 \mu$ of serum using QIAamp Viral RNA Extraction Kit (Qiagen) following the method described by the manufacturer.

\section{Viral Load Estimation}

Viral load was measured by using a single step reverse transcriptase real-time $P C R$, targeting the 5 'HCV non-coding (NC) region (Applied Biosystems). One-step RT-PCR performed reverse transcription as well as GPCR in a single buffer system, and the reaction proceeds without the addition of reagents between the RT and qPCR steps. This offers the convenience of a single-tube preparation for RT and PCR amplification and is time saving and lowers the chances of cross contamination. It also shows accuracy across a wide dynamic range enabling low copy number detection and precise quantification, consistency over a variety of assays, including ATrich, GC-rich and long amplicons.

\section{Primers and Probes}

Primers: Primer sequences for 212 bp stretch of the 5 'UTR region was used;

HCV_F 5'-3' AGTGTTGTGCAGCCTCCAG

HCV_R 5'-3'ACTGCCTGATAGGGTGCTTG

Probes: Two sets of probes were designed based on known isolates sequences. Each probe sequence is specific (data not shown) for a particular HCV genotype(s):

Genotype 3 probe sequence

MBG3: 5' CGCGATCCGAGATCACTAGCCGAGTAGTGTGATCGCG 3'

Genotypes 1, 4 and 6 probe sequence

MBG1: 5' CGCGATCAGACTGCTAGCCGAGTAGTTTGG ATCGCG 3'

\section{Assay of IFN-Alpha Level in Serum}

IFN-alpha levels were measured by a commercial enzyme-linked immunosorbent assay kit. (Amersham sandwich ELISA kit for human IFN-alpha, UK).

\section{RESULTS}

\section{Viral Load Standard and Viral Load Standard Curve}

A reference serum sample with known viral load of 2,148,000 IU was used. Five points of 10-folds dilutions were run in duplicate along with the unknown viral load samples (Figure 1). Standard curve efficiency rate $=97.9 \%, \mathrm{R} 2=0.993$, Y-Interval $=44.02$ and Slope $=-3.373$.

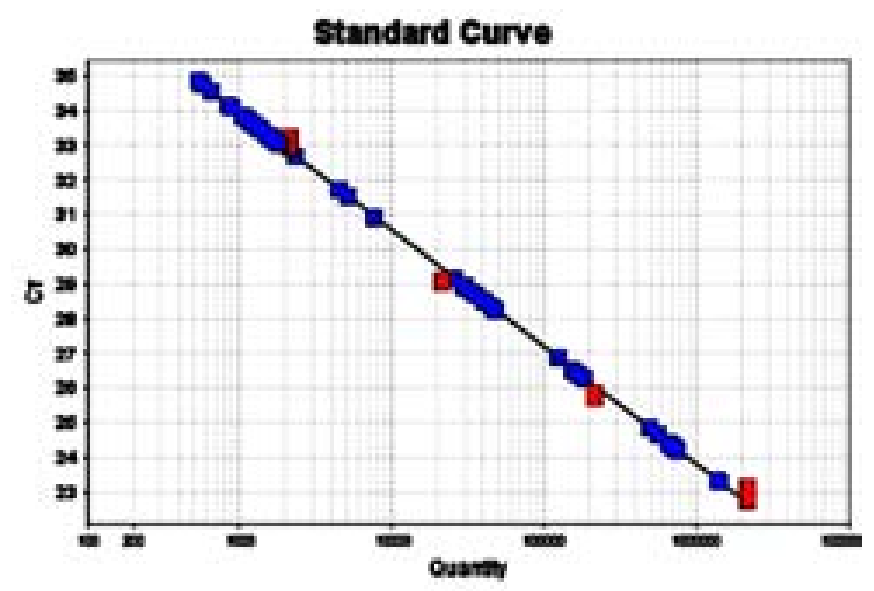

Figure 1. Viral Load Standard Curve

\section{The Dynamic Changes of Viral Load with Time}

Viral load was measured in international units (IU) and was transferred into $\log ^{10}$ to obtain normal distribution. One Way Repeat Measure ANOVA test and Mauchly's test of Sphericity were used to measure the dynamic changes of viral load with time. Because of violation of sphericity, the Greenhouse-Giesser correction was used. The dynamic changes of viral load with time (Table 1; Figure 2 ) were found to be significant $(P=0.001)$. 
Table 1. Pre-haemodialysis viral loads of the three batches

\begin{tabular}{|c|c|c|c|c|}
\hline \multirow[t]{2}{*}{ No. } & \multirow[t]{2}{*}{ Patient's Code } & \multicolumn{3}{|c|}{ Pre-haemodialysis Viral Load $\left(\log ^{10} / \mathrm{mL}\right)$} \\
\hline & & $1^{\text {st }}$ Batch & $2^{\text {nd }}$ Batch & $3^{\text {rd }}$ Batch \\
\hline 1 & PT1 & 5.70 & 5.86 & 5.51 \\
\hline 2 & PT2 & 3.07 & 3.08 & 2.11 \\
\hline 3 & PT3 & 4.51 & 4.45 & 3.48 \\
\hline 4 & PT4 & 2.64 & 3.15 & 2.64 \\
\hline 5 & PT5 & 2.56 & 2.77 & 2.21 \\
\hline 6 & PT6 & 2.61 & 3.16 & 2.36 \\
\hline 7 & PT7 & 2.84 & 3.19 & 2.68 \\
\hline 8 & PT8 & 3.98 & 4.60 & 4.00 \\
\hline 9 & PT9 & 4.48 & 4.62 & 4.06 \\
\hline 10 & PT10 & 5.22 & 5.23 & 5.27 \\
\hline 11 & PT11 & 5.30 & 5.20 & 4.29 \\
\hline 12 & PT12 & 5.50 & 5.72 & 4.28 \\
\hline 13 & PT13 & 4.05 & 3.68 & 3.27 \\
\hline 14 & PT14 & 2.57 & 2.85 & 2.09 \\
\hline 15 & PT15 & 2.55 & 2.86 & 2.46 \\
\hline 16 & PT16 & 2.79 & 6.14 & 2.72 \\
\hline 17 & PT17 & 6.10 & 6.08 & 5.33 \\
\hline 18 & PT18 & 3.60 & 4.00 & 3.03 \\
\hline 19 & PT19 & 3.73 & 3.66 & 3.47 \\
\hline 20 & PT20 & 3.56 & 3.56 & 3.66 \\
\hline 21 & РT21 & 4.09 & 3.78 & 3.57 \\
\hline 22 & PT22 & 6.52 & 6.12 & 5.63 \\
\hline 23 & PT23 & 4.94 & 4.67 & 4.04 \\
\hline 24 & РT24 & 3.30 & 3.21 & 1.68 \\
\hline 25 & РT25 & 4.76 & 5.10 & 4.63 \\
\hline 26 & РT26 & 5.29 & 5.59 & 4.74 \\
\hline 27 & PT27 & 4.89 & 4.67 & 4.70 \\
\hline
\end{tabular}
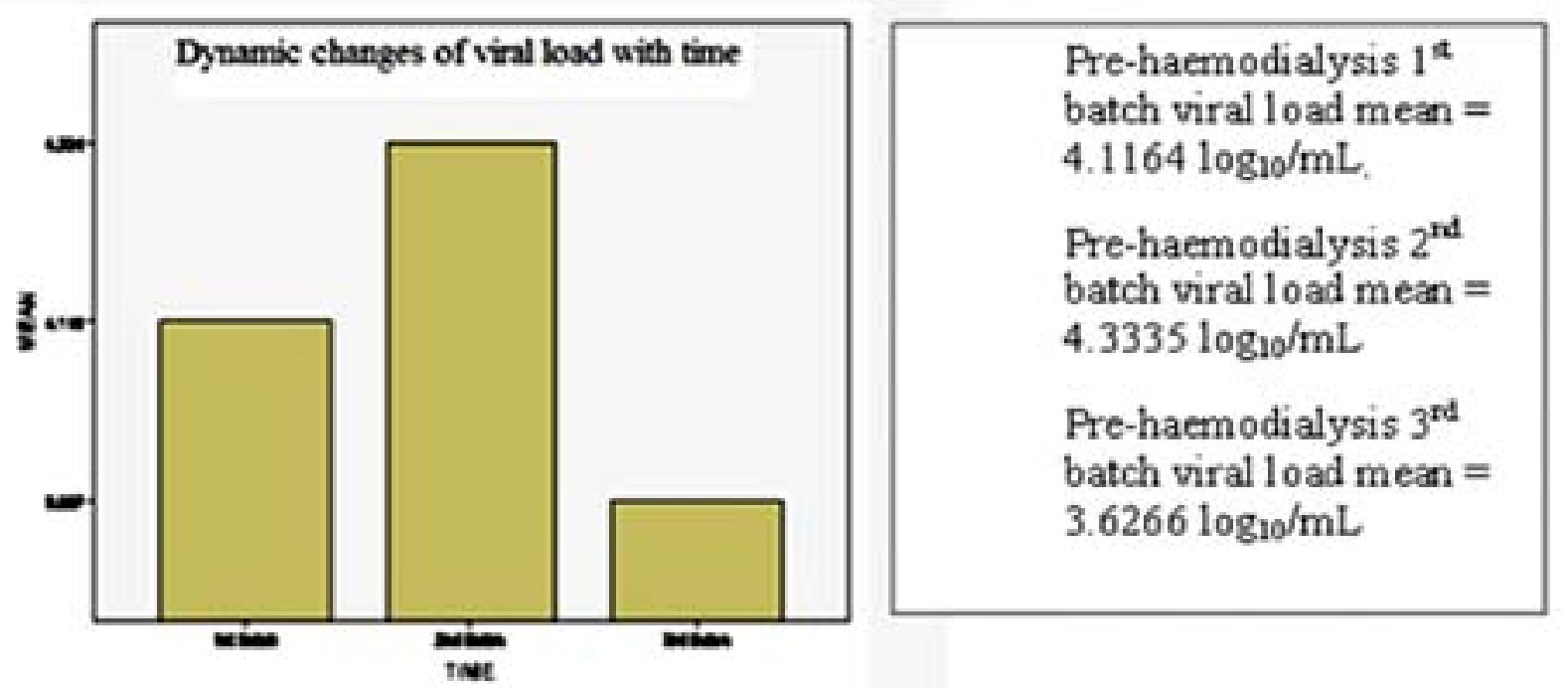

Figure 2. Prehaemodialysis viral load variation in three batches of sera taken one month apart. 
The Difference between Pre and Post-Haemodialysis Viral Loads

Mean of pre-haemodialysis viral load $=4.0255 \log _{10}$ with standard error $=0.13$ and post-haemodialysis viral load mean $=4.01 \log _{10}$ with standard error $=$
0.13 . The mean of pre-haemodialysis viral load was greater than post-haemodialysis viral load but the difference is statistically insignificant $(p=0.367)$.

Table 2. The difference between pre and post-haemodialysis viral loads

\begin{tabular}{llllllll}
\hline No. & Patient's & \multicolumn{6}{c}{ Viral Load $\left(\right.$ Log $\left.^{10} / \mathrm{mL}\right)$} \\
\cline { 3 - 7 } & code & $1^{\text {st }}$ Batch & \multicolumn{3}{c}{$2^{\text {nd }}$ Batch } & $3^{\text {rd }}$ Batch \\
\cline { 3 - 7 } & & Pre-HD & Post-HD & Pre-HD & Post-HD & Pre-HD & Pre-HD \\
\hline 1 & PT1 & 5.70 & 5.79 & 5.86 & 5.86 & 5.51 & 5.85 \\
2 & PT2 & 3.07 & 3.21 & 3.08 & 3.07 & 2.11 & 2.41 \\
3 & PT3 & 4.51 & 4.21 & 4.45 & 4.57 & 3.48 & 3.26 \\
4 & PT4 & 2.64 & 2.50 & 3.15 & 3.12 & 2.64 & 2.69 \\
5 & PT5 & 2.56 & 2.37 & 2.77 & 3.04 & 2.21 & 2.61 \\
6 & PT6 & 2.61 & 2.62 & 3.16 & 3.13 & 2.36 & 2.77 \\
7 & PT7 & 2.84 & 2.76 & 3.19 & 3.15 & 2.68 & 2.61 \\
8 & PT8 & 3.98 & 3.86 & 4.60 & 4.48 & 4.00 & 3.95 \\
9 & PT9 & 4.48 & 4.68 & 4.62 & 4.63 & 4.06 & 3.56 \\
10 & PT10 & 5.22 & 4.92 & 5.23 & 5.19 & 5.27 & 4.67 \\
11 & PT11 & 5.30 & 5.71 & 5.20 & 5.25 & 4.29 & 4.38 \\
12 & PT12 & 5.50 & 5.78 & 5.72 & 5.83 & 4.28 & 4.20 \\
13 & PT13 & 4.05 & 3.87 & 3.68 & 3.88 & 3.27 & 3.06 \\
14 & PT14 & 2.57 & 2.66 & 2.85 & 3.22 & 2.09 & 2.45 \\
16 & PT16 & 2.79 & 2.69 & 6.14 & 3.24 & 2.72 & 2.73 \\
17 & PT17 & 6.10 & 6.13 & 6.08 & 6.11 & 5.33 & 5.43 \\
18 & PT18 & 3.60 & 3.34 & 4.00 & 3.67 & 3.03 & 3.59 \\
19 & PT19 & 3.73 & 3.43 & 3.66 & 3.88 & 3.47 & 3.61 \\
20 & PT20 & 3.56 & 3.34 & 3.56 & 3.31 & 3.66 & 3.64 \\
21 & PT21 & 4.09 & 3.87 & 3.78 & 3.61 & 3.57 & 3.92 \\
22 & PT22 & 6.52 & 6.61 & 6.12 & 6.56 & 5.63 & 6.28 \\
23 & PT23 & 4.94 & 4.78 & 4.67 & 4.30 & 4.04 & 4.26 \\
24 & PT24 & 3.30 & 2.77 & 3.21 & 3.33 & 1.68 & 1.48 \\
25 & PT25 & 4.76 & 5.30 & 5.10 & 5.01 & 4.63 & 4.00 \\
26 & PT26 & 5.29 & 5.34 & 5.59 & 5.36 & 4.74 & 4.76 \\
27 & PT27 & 4.89 & 5.09 & 4.67 & 5.13 & 4.70 & 4.50
\end{tabular}

The Relationship between HCV Genotypes and PreHaemodialysis Viral Load

The means of pre-haemodialysis viral load for genotypes 1 and 3 were calculated and compared by using Independent-Samples T Test. Genotypes 4 and 6 were omitted from the analysis since there was only one patient with each of them.

Genotype 1 pre-haemodialysis mean viral load was 4.6434, which is greater than genotype 3 pre-haemodialysis mean viral load of 3.8347 and a $\mathrm{P}$-value of 0.0165 , indicating a significant difference between genotype 1 and genotype 3 pre-haemodialysis viral loads (Table 2, Figure 3 ).

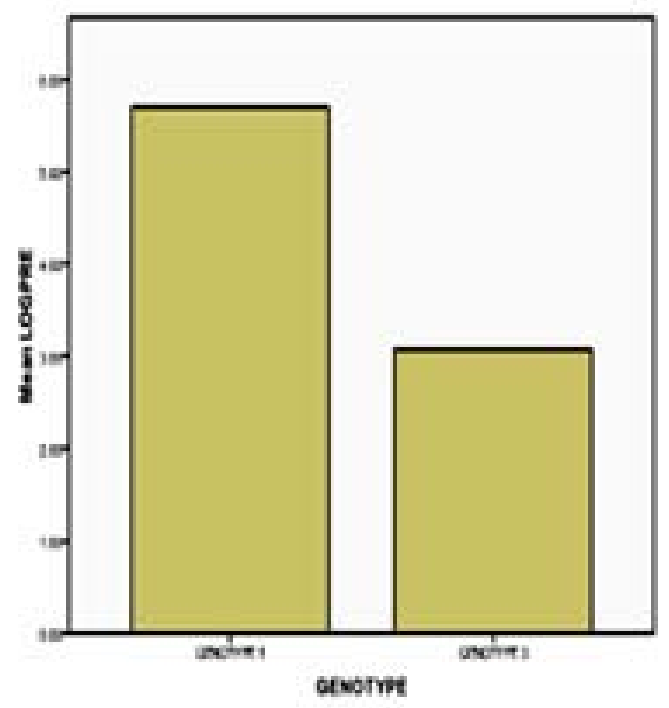

Figure 3. The relationship between HCV genotypes and viral load 
THE RELATIONSHIP BETWEEN PLASMA IFN- a AND VIRAL LOAD

Linearized IFN- a standard curve was obtained by plotting seven standard concentrations against their respective optical density (O.D.) values (Figure 4). Unknowns were interpolated from the standard curve. The plasma IFN-a levels were measurable in only 2-5/27 patients in the three batches of sera tested, ranging between $22-541 \mathrm{pg} / \mathrm{mL}$. No further statistical tests were performed because of the few number of patients with detectable levels and the obvious no apparent relation between the viral loads and the corresponding interferon-alpha levels.

Figure 4. Interferon-alpha standard curve

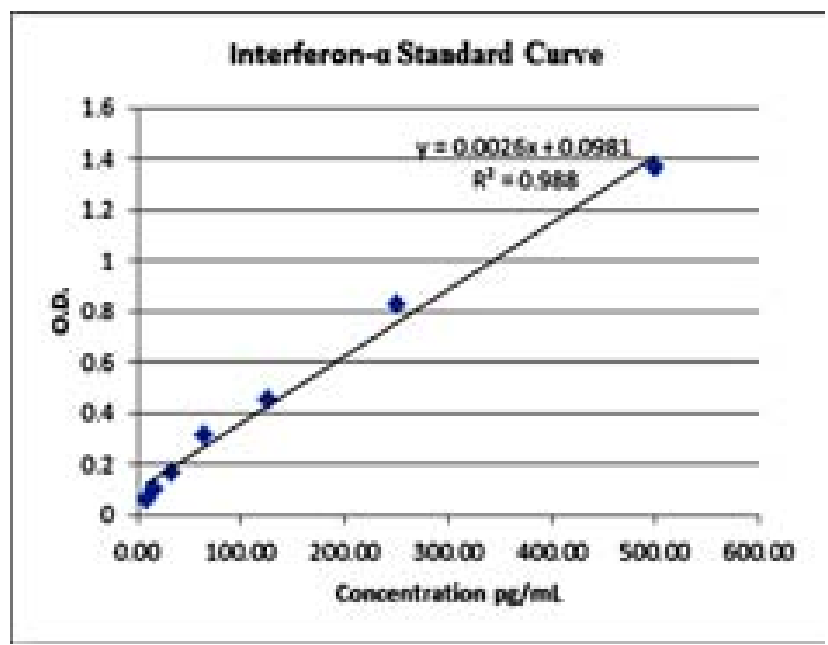

The Relationship between Functional Status of the Liver and Viral Load

Spearman's and Kendall's tests were used to measure the relationship between liver function tests (AST, ALT, ALP, albumin, total protein, total bilirubin) and pre-haemodialysis viral load. No significant correlation could be demonstrated between pre-haemodialysis viral load and the above stated liver function parameters (either the $p$ value was $>0.05$ or the patients had normal values).

\section{DISCUSSION}

\section{Viral Load Fluctuation}

The present study explored the short-term fluctuations in $\mathrm{HCV}$ viral load in infected HD patients over a period of three months. All patients showed persistent but low viral load levels; however, the variation with time in HCV RNA viral load (Figure 2) was significant $(P=$ 0.001 ). These findings are consistent with those of Fabrizi et al. ${ }^{7}$ who studied the biological dynamics of viral load in 52 patients infected with hepatitis $C$ virus associated with end-stage renal disease, and found that larger fluctuations in HCV RNA levels occurred in patients with persistent HCV viraemia than in those with intermittent viraemia. However, we cannot arrive at such a conclusion since our patients were not similarly grouped because their viraemic status was found to be both persistent and relatively consistently low.

\section{Pre- and Post-Haemodialysis Viral Load}

The post-haemodialysis viral load was generally reduced when compared to pre-dialysis levels but the difference was statistically insignificant $(P>0.05)$, possibly because most of the patients exhibited relatively low viral loads. These findings are consistent with those of Angelico et al. ${ }^{3}$ who also found that patients with low pre-dialysis HCV RNA levels (< $2.5 \times 103$ copies $/ \mathrm{mL}$ ) exhibited only minimal changes following the procedure. However, he also observed significant reduction $(P=0.04)$ of serum hepatitis $C$ virus-RNA levels after a single haemodialysis in patients with high pre-dialysis viral load. Furthermore, Fabrizi et al. ${ }^{8}$ had quantitatively studied the HCV load in 394 chronic haemodialysis patients by branched DNA assay and found it to be consistently relatively low.

\section{Relationship between viral load and liver function tests}

We attempted in this study to explore the relationship between viral load and six liver function tests (AST, ALP, TP, albumin, ALT and TB). These parameters of liver function were measured in all the test subjects at the previously mentioned three points in time, but no relationship was observed between their levels and those of the simultaneously measured viral load. As a matter of fact, all the above parameters, with the exception of alkaline phosphatase, showed minor or no deviation from the normal. Thus, these findings together with the relatively low viral loads probably reflect a mild clinical disease course in these patients at the time period of the study. Hill and Sammons ${ }^{9}$ had studied the elevation of serum alkaline phosphatase in diseases and found that ALP released from bone and liver, hence, it is not specific for liver damage and can be elevated in bone diseases as well. In addition, Gupta ${ }^{10}$ stated that osteodystrophy is common in patients with chronic renal failure undergoing haemodialysis. Altiparmak et al. ${ }^{2}$ had studied the relationship between histological damage, viral load and serum transaminase levels in patients with chronic hepatitis C.Theycomparedfibrosisscoresandhistologyindexwith viral load and serum transaminase levels and concluded that there was no significant relationship between serum AST and ALT levels and viral loads of both the Knodell score groups and the fibrosis groups ( $p>0.05, p>0.05) .{ }^{11,12}$ This finding revealed that the above parameters cannot take the place of histopathological findings in the evaluation of liver damage in chronic hepatitis $C$ infection. Moreover, Zeuzem et al. ${ }^{13}$ had studied the correlation between viraemia, liver function tests, and histology and found that there is no significant relationship between ALT, AST and albumin levels and the viral load and that some patients had persistent normal aminotransferase levels. They found four couples in which spouses with 
normal ALT had higher histological scores and higher HCV-RNA levels than their partners with abnormal ALT. Angelico et al. ${ }^{3}$ found that patients undergoing maintenance haemodialysis are often infected with hepatitis $C$ virus, yet the clinical course of liver disease is usually mild and hepatitis $C$ virus-RNA levels were unrelated to the duration of haemodialysis and the presence of abnormal levels of transaminases. Moreover, studies of the liver histology in patients on haemodialysis with chronic hepatitis $C$ viral infection concluded that the early course of the disease is relatively mild in patients infected with HCV and undergoing maintenance haemodialysis. ${ }^{9-11}$ This milder disease course in HD patients is probably related to the treatment they received or the induction of protective host defenses as suggested by Badalamenti et al. ${ }^{5}$

\section{The Relationship between HCV Genotypes and Pre-Haemodialysis Viral Load}

In this study, genotype 3 was the most prevalent one affecting 21 patients $(77.8 \%)$ followed by genotype 1 in four patients (14.8\%). ${ }^{11}$ The viral load of HCV genotype 1 was significantly higher than that of genotype 3 in the first batch. While in the second and third batches, genotype 1 viral load was higher than genotype 3 but the difference was insignificant $(P>$ 0.05). After pooling the results of pre-haemodialysis viral load from all the three batches, it was found that genotype 1 was significantly associated with a higher viral load $(P=0.01)$ as compared to genotype ${ }^{3}$. Similar findings were reported by Berger et al. ${ }^{7}$ who studied the relationship between different genotypes and viral load. Statistically significant higher HCV RNA titres were observed in haemophiliacs infected with HCV genotype 1 as compared to those infected with other genotypes $(P<0.01)$. The higher viral load in HCV genotype 1 infected patients may be a factor in the known more difficulty of eradicating genotype 1 than genotypes 2 and 3 infections. ${ }^{12}$

\section{Relationship between Viral Load and Serum Interferon-Alpha Levels}

The pre-haemodialysis serum interferon- $a$ levels were measured in 27 patients at three points in time, one month apart and then compared with pre-haemodialysis viral load. It was found that only two patients in the first batch, five patients in second batch and two in the third batch exhibited measurable levels of plasma IFN- $a$. These results reflect either true very low IFN-a level in these patients due to poor stimulation of interferon production by the low grade viral infection, or they are due to the limited sensitivity of the ELISA assay used. Undetectable plasma IFN- a level has also been reported by Killian et al. ${ }^{11}$, but in HIV-infected patients. They studied the changes in plasmacytoid dendritic cell and CD4 T-cell counts and the IFN-a levels in these patients and found that circulating plasma IFN- $\alpha$ was undetectable by ELISA regardless of the duration of HIV-1 infection.

Volume 11 Number 1 June 2012

\section{CONCLUSION}

HCV infected haemodialysis patients experience significant fluctuation in viral load with time but no correlation with biochemical evidence of liver injury. HCV genotype 1 is associated with higher viral load as compared to genotype ${ }^{3}$. Single-step rt qPCR assay has the potential for rapid HCV genotyping.

\section{ACKNOWLEDGEMENT}

We would like to thank all the workers and members of staff and patients in the various haemodialaysis clinics in Pahang; whose contributions made this study possible.

\section{REFERENCES}

1. Aini $H H$, Mustafa MIA, Seman MR, Nasuruddin BA. HCV Genotypes in Haemodialysis Units: A Preliminary Study. Int J Infect Dis 2008;12(1): e91.

2. Altiparmak E, Saritaș Ü, Altintaș E, et al. Relationship between histological damage, viral load and serum transaminase levels in patients with chronic hepatitis $C$. The Turkish Journal of Gastroenterology 2001;12(3):185188.

3. Angelico M, Morosetti M, Passalacqua S, et al. Low levels of hepatitis $C$ virus RNA in blood infected patients under maintenance haemodialysis with high-biocompatibility, high-permeability filters. Dig Liver Dis 2000;32(8):724-8.

4. Craxì A, Cammà C. Treating patients with HCV genotype 1 and low viraemia: More than meets the eye. J Hepatol 2006;44:4-7.

5. Badalamenti S, Catania A, Lunghi G, et al. Changes in viremia and circulating interferonalpha during haemodialysis in hepatitis $C$ virus-positive patients: only coincidental phenomena? Am J Kidney 2003;42:143-50.

6. Berger A, von Depka Prondzinski $M$, et al. Hepatitis C plasma viral load is associated with HCV genotype but not with HIV coinfection. J Med Virol 1996;48:339-43.

7. Fabrizi F, Martin P, Dixit V, et al. Biological dynamics of viral load in haemodialysis patients with hepatitis $C$ virus. Am J Kidney Dis 2000;35:122-9.

8. Fabrizi F, Martin P, Dixit V, et al. Quantitative Assessment of HCV Load in Chronic Haemodialysis Patients: A Cross-Sectional Survey. Nephron 1998;80:428-33.

9. Hill PG, Sammons HG. An interpretation of the elevation of serum alkaline phosphatase in disease. J Clin Pathol 1967;20:654-9.

10. Gupta, V. Renal osteodystrophy and aluminium bone disease in patients with chronic renal failure. JK-Practitioner 2003;10(2):107-11.

11. Killian MS, Fujimura SH, Hecht FM, Levy JA. Similar changes in plasmacytoid dendritic cell and CD4 T-cell counts during primary HIV-1 
infection and treatment. AIDS

2006;20(9):1247-52.

12. Knodell RG, Ishak KG, Black WC, et al.

Formulation and application of a numerical scoring system for assesing histologic activity in asymptomatic chronic active hepatitis.

Hepatology 1981;1(5):431-5.

13. Zeuzem S, FrankeA, Lee JH, et al. Phylogenetic analysis of Hepatitis $\mathrm{C}$ virus isolates and their correlation to viremia, liver function tests, and histology. Hepatology 1996;24(5): 1003-9. 
